\title{
Análise funcional da interação profissional-paciente em odontopediatria
}

\author{
The patient-professional relationship functional \\ analysis in the pediatric dentistry
}

\author{
Daniele Pedrosa FIORAVANTE \\ Maria Rita Zoéga SOARES \\ Jocelaine Martins da SILVEIRA² \\ Norma Sant'Anna ZAKIR'
}

\begin{abstract}
Resumo
O artigo visou identificar o padrão de interação entre odontopediatras e crianças atendidas em uma clínica do bebê de uma universidade pública brasileira. Participaram do estudo duas crianças consideradas pelos dentistas cooperativas, duas consideradas opositoras em relação ao procedimento e os profissionais que as atenderam. Um inventário foi aplicado a fim de excluir crianças com problemas comportamentais em grau clínico. As interações entre criança e odontopediatra foram filmadas e os dados foram analisados, medindo-se a freqüência das respostas de cooperação e não-cooperação, no decorrer de quatro procedimentos. Observou-se que os comportamentos cooperativos das crianças se relacionam com as chamadas condutas positivas dos profissionais, enquanto os comportamentos opositores estiveram fortemente associados às ditas condutas negativas dos odontopediatras. Os resultados foram discutidos considerando os comportamentos das crianças e dos profissionais em pontos críticos para execução dos procedimentos e para o bem-estar do paciente.
\end{abstract}

Unitermos: análise funcional; crianças; metanálise; odontopediatra; psicologia clínica.

\begin{abstract}
The aim of this article was to identify the interaction patterns of four dyads pediatric dentristry - pacient during ten minutes of a clinical procedure. Professionals were required to indicate a cooperative and an opponent child, concerning the treatment. Children's behaviors were assessed so that clinical referred children could be excluded from the study. The data were video recorded and the interactions were evaluated. As a result, it was seen that the professionals' positive attitudes were most related to the cooperative behavior, while the negative attitudes were associated to an opponent pattern. Results were discussed considering patient's well-being and some points about the procedure.

Uniterms: functional analysis; children; meta-analysis; pediatric dentistry, psychology clinical.

$\operatorname{cov}$

- Universidade Estadual de Londrina, Centro de Ciências Biológicas, Departamento de Psicologia Geral e Análise do Comportamento. Rodovia Celso Garcia Cid, Pr 445, km 380, Campus Universitário, Caixa Postal 6001, 86051-990, Londrina, PR, Brasil. Correspondência para/Correspondence to: D.P. FIORAVANTE. E-mail: <danifio@sercomtel.com.br>.

2 Universidade Federal do Paraná, Setor de Ciências Humanas, Letras e Artes, Departamento de Psicologia. Curitiba, PR, Brasil.
\end{abstract}


O contexto odontológico detém muitos eventos aversivos, de modo que o medo de dentista constitui uma queixa freqüente em grande parte da população mundial (Thom, Sartory \& Johren, 2000). O ambiente do consultório odontológico pode eliciar ansiedade e pode também relacionar-se a padrões de comportamentos operantes de fuga ou esquiva.

Berge, Veerkamp e Hoogstraten (1999) e Stokes e Kennedy (1980) consideram que essa aversividade do contexto odontológico atinge especialmente a criança, que fica exposta a uma situação que, dependendo do procedimento odontológico em execução ou da habilidade dos profissionais, provoca dor, ansiedade e medo.

A aversividade no contexto odontológico pode estar relacionada à não-cooperação - apresentada por mais de $25 \%$ de crianças em tratamento odontopediátrico -, que pode ser entendida como comportamentos de fuga e esquiva emitidos pela criança, que dificultam ou impedem a realização dos procedimentos pelo dentista (Possobon, Moraes, Costa Jr. \& Ambrosano, 2003). Sabe-se que a ansiedade do paciente odontológico relaciona-se ao prolongamento de cerca de 20\% na duração do tratamento, oferecendo riscos que transcendem a esfera odontológica (Ambrosano, Costa Jr., Moraes \& Possobon, 2004).

A identificação das variáveis comportamentais relacionadas à administração do tratamento odontológico pode minimizar aspectos desnecessariamente aversivos no contexto da odontopediatria. Essas variáveis podem ser observadas tanto no comportamento da criança quanto no do profissional. Todavia boa parte da pesquisa comportamental nesse contexto tem-se debruçado sobre o comportamento da criança, promovendo sua alteração de modo a viabilizar a intervenção odontológica (Moraes, 1999).

Há trabalhos destinados a avaliar o efeito de estratégias para modificar o comportamento da criança (Allen, Loiben, Allen \& Stanley, 1992; Allen, Stark, Rigney, Nash \& Stokes 1988; Ingersoll, Nash \& Gramber, 1984; Melamed, Hawes, Heiby \& Glick, 1975; Stark et al., 1989), e os resultados são medidos em termos da melhora na sua colaboração.

Berge et al. (1999) indicam que a postura do profissional (e não somente o comportamento da 268 criança) também interfere na execução dos procedi- mentos. Segundo os autores, o manejo inadequado dos instrumentos odontológicos, a utilização de coerção e a negação dos sentimentos infantis inibem os comportamentos colaborativos da criança e potencializam o medo do tratamento odontológico (Prins, Weerkamp, Horst, Jong \& Tan, 1987; Weinstein, Getz, Ratener \& Domoto, 1982).

Weinstein et al. (1982) e Weinstein (1986) observaram que o fornecimento prévio de informação, o direcionamento da conduta e a compreensão das reações emocionais da criança facilitaram a aquisição e a manutenção de comportamentos colaborativos com o tratamento, ao passo que diminuíram as reações indicativas de medo, como chorar, gritar ou protestar.

Moraes e Gil (1991) lembram, porém, a existência de situações em que a rebeldia da criança exige atitudes invasivas por parte do dentista, as quais abrangem, segundo a Academia Americana de Odontopediatria (1996), desde estratégias de controle pela voz até o uso de restrições físicas. Christiano e Russ (1998), no entanto, alertam para o fato de esse último procedimento expor a criança por muito mais tempo à estimulação aversiva, sem promover comportamentos de colaboração por parte dela.

É possível que a identificação e o manejo de variáveis comportamentais relacionadas tanto ao odontopediatra quanto à criança sejam um passo importante na redução da aversividade do contexto odontológico (Costa Jr. \& Coutinho, 2000).

De modo geral, os odontopediatras manifestam a vontade de melhorar e expandir seus conhecimentos sobre manejo do comportamento de crianças, e, nesse sentido, a odontologia tem buscado subsídios junto à psicologia no intuito de definir um conjunto de estratégias para o manejo de comportamentos de pacientes que apresentam dificuldades em enfrentar um tratamento odontológico (Allen, Stanley \& McPherson, 1990).

Costa Jr. (2001) sugere que uma proposta para estudar o comportamento dos profissionais de saúde, no contexto do atendimento clínico, deveria incluir a análise funcional do comportamento de todos os indivíduos envolvidos na situação. Isso, porém, parece não estar sendo efetivamente realizado, já que poucos autores analisam o quanto o comportamento do profissional é também afetado funcionalmente pela 
conduta das crianças (Prins et al., 1987; Weinstein et al., 1982).

O método utilizado pelo analista comportamental, a Análise Funcional do Comportamento, pode ser empregado no estudo da interação entre odontopediatra e criança em um contexto odontológico (Meyer, 1997). O presente estudo visou analisar funcionalmente a interação entre o profissional e o paciente em odontopediatria.

Os objetivos deste estudo foram: a) verificar quais comportamentos dos profissionais funcionariam como possíveis variáveis presentes no contexto odontológico e contribuiriam para aumentar a probabilidade de emissão de determinadas respostas por parte das crianças; b) identificar quais comportamentos das crianças provavelmente levariam a uma alteração no ambiente do profissional, funcionando como variável independente à modificação do comportamento desse último.

\section{Método}

Este trabalho foi realizado na clínica odontológica para atendimento ao público infantil - Bebê Clínica - da Universidade Estadual de Londrina (UEL). Tanto suas etapas quanto o Termo de Consentimento Livre e Esclarecido foram submetidos e aprovados pelo Comitê de Ética em Pesquisa da UEL, processo número 031/05. Esse termo deveria ser assinado por todos os participantes ou por seus responsáveis, visando fornecer informações sobre os vários aspectos da pesquisa bem como solicitar a divulgação dos seus resultados.

Fundada em 1983, a Bebê Clínica da Universidade Estadual de Londrina constitui-se o primeiro centro brasileiro de odontologia para bebês. Atualmente atende, de segunda a sexta- feira, crianças de zero a cinco anos de idade, servindo de campo de estágio acadêmico de graduação e pós-graduação, além de prestador de serviços à comunidade de Londrina e região.

\section{Participantes}

Solicitou-se a participação de dois profissionais de odontologia do sexo feminino (P1 e P2), com idades de 26 e 32 anos, que estivessem cursando a especialização em odontopediatria da Universidade Estadual de Londrina. Cada uma delas indicou duas crianças do sexo masculino, consideradas respectivamente cooperativas e opositoras no que concerne à realização do procedimento clínico. As crianças selecionadas tinham idades entre um ano e meio e quatro anos.

P1 atendeu a duas crianças. A primeira delas, com quatro anos de idade, foi considerada cooperativa e submetida a procedimentos preventivos ${ }^{3}$. A segunda criança, com um ano e meio de idade, e considerada opositora, foi submetida à remoção de splintagem4.

P2, por sua vez, atendeu a duas outras crianças, sendo a primeira delas considerada cooperativa, e a segunda opositora. Ambas tinham quatro anos de idade e foram submetidas a procedimentos preventivo ${ }^{3}$.

\section{Instrumentos}

Os equipamentos utilizados foram: filmadora, tripé e vídeo-cassete, destinados à gravação e à posterior categorização das sessões de observação.

Walker Problem Behavior Identification Checklist (WPBIC) (Walker, 1976): traduzido para o português por Silvares (s/d), identifica a necessidade de atendimento psicoterápico no que se refere à amostra em questão. Uma pontuação ponderada de 60 ou mais remonta à existência de um problema clínico em uma ou mais das áreas mensuradas pelo instrumento, a saber: impulsividade, isolamento, atenção instável, relações perturbadas com os pares e imaturidade. Seu objetivo foi efetuar uma avaliação do comportamento infantil, identificando e descartando da pesquisa crianças que necessitem de ajuda psicológica.

Protocolo de Registro dos Comportamentos da Criança Durante a Realização do Procedimento Clínico - adaptado da escala OSBD - Observation Scale of

Q

3 Procedimentos preventivos englobariam a escovação, o uso do fio dental, a aplicação de flúor ou a observação da condição dentária geral, por exemplo. É um procedimento indolor (Borges, 1999).

- A remoção de splintagem abrange a retirada de um splint, ou seja, de um aparelho odontológico utilizado para prevenir a movimentação ou deslocamento de dentes, porções fraturadas ou partes móveis. É um procedimento indolor (Ferreira, Carvalho, Mitsudo \& Bergamo, 2006). 
Behavioral Distress (Jay, Ozolins, Elliot e Caldwell, 1983): composto por oito categorias comportamentais definidas operacionalmente, que incluíam respostas verbais ou motoras da criança indicadoras de oposição durante a realização do procedimento odontológico (chorar, choramingar, comportar-se de modo nervoso, agredir fisicamente, gritar, movimentar-se até a imobilização, fugir e protestar). Outras sete categorias indicativas de comportamentos cooperativos também foram operacionalmente definidas: falar, responder verbalmente, solicitar informação, buscar suporte emocional, olhar, olhar para outro estímulo e auxiliar na execução do procedimento clínico. 0 instrumento era respondido pelos odontopediatras com base numa escala likert de quatro pontos (menos freqüente a mais freqüente), no intuito de verificar a freqüência de comportamentos concorrentes ou cooperativos no que se referia a tal contexto.

Quadro para Categorização das Condutas dos Profissionais: elaborado pela equipe de pesquisa com base tanto na observação do contexto odontopediátrico quanto na adaptação de protocolos já existentes para avaliação dos comportamentos de diferentes profissionais da área da saúde (Ambrosano et al., 2004; Gongora \& Silvares, 1998). Assim, incluiu-se a descrição operacional de seis diferentes condutas dos profissionais consideradas positivas: descrição do procedimento e do funcionamento do equipamento, fazer perguntas, fantasiar, oferecer conforto emocional ou contato físico, elogiar, distrair a criança com outro assunto ou estímulo. Outras cinco condutas consideradas negativas também foram descritas operacionalmente, abrangendo a crítica/restrição verbal, a restrição/imobilização física, as ordens/direcionamentos, o deixar a criança sozinha e o falar com outras pessoas sobre a criança como se ela não estivesse presente. Tais categorias foram submetidas à calibração, a fim de atestar a clareza de suas definições. liação das condutas dos profissionais durante a realização dos procedimentos odontológicos já mencionados. Seu registro era efetuado por duas observadoras que, com base na descrição e nos exemplos fornecidos acima, calcularam a freqüência de emissão dessas condutas durante o período de duração de cada 270 uma das filmagens.
Quadro para Categorização das Condutas das Crianças: de modo semelhante ao descrito na Tabela 1, o presente instrumento serviu para uma melhor identificação da freqüência das condutas das crianças emitidas durante a realização dos procedimentos odontológicos (Tabela 2). Também com base em observações específicas ao contexto odontopediátrico em questão e em algumas categorizações já existentes (Ambrosano et al., 2004; Gongora \& Silvares, 1998; Jay et al., 1983), esta Tabela continha a descrição operacional de seis condutas das crianças consideradas cooperativas, tais como falar, responder verbalmente, solicitar informação, buscar suporte emocional, olhar para a execução do procedimento e auxiliar na execução do procedimento, bem como de outras seis categorias de comportamentos opositores, incluindo o chorar e o choramingar, o comportar-se de modo nervoso, o agredir fisicamente, o fugir ou movimentar-se até a imobilização e o protestar.

Tal quadro foi submetido à calibração, sendo o registro da freqüência de cada uma dessas respostas efetuado por duas observadoras com base na descrição e nos exemplos fornecidos acima.

\section{Procedimentos}

Inicialmente foi feito contato com a instituição "Bebê Clínica" da Universidade Estadual de Londrina, através da coordenadora do curso de especialização em odontopediatria. Essa primeira visita teve o intuito de explicar os objetivos do trabalho bem como solicitar a autorização para que ele se efetuasse.

O trabalho iniciou-se mediante a explicitação dos objetivos da pesquisa para os membros da clínica, esclarecendo a necessidade de participação de dois voluntários, cujo horário de atendimento fosse compatível com o da equipe de pesquisa, a fim de viabilizar a coleta de dados. Foi requisitada a eles a assinatura do Termo de Consentimento Livre e Esclarecido.

Solicitou-se que cada um dos profissionais, mediante experiência de atendimento anterior, indicasse uma criança considerada cooperativa e uma considerada opositora em relação aos procedimentos odontológicos. Desse modo, foi efetuado o contato com as mães dessas crianças, explicitando-se os objetivos 
Tabela 1. Comportamentos dos profissionais categorizados quanto à emissão de condutas positivas/negativas durante o tratamento odontológico infantil.

\begin{tabular}{|c|c|c|}
\hline \multicolumn{3}{|c|}{ Categorias profissionais } \\
\hline Condutas positivas & & Exemplos \\
\hline $\begin{array}{l}\text { Descrição do procedimento e do fun- } \\
\text { cionamento do equipamento }\end{array}$ & $\begin{array}{l}\text { Verbalizações que descrevem o que ele ou a criança está } \\
\text { fazendo, o que está acontecendo no momento, ou os } \\
\text { comportamentos encobertos envolvidos na situação. }\end{array}$ & $\begin{array}{l}\text { Agora eu vou pegar a escovinha! } \\
\text { Acho que você está com medo! }\end{array}$ \\
\hline Fazer perguntas & $\begin{array}{l}\text { Comentários descritivos ou reflexivos expressos em forma } \\
\text { de pergunta e que não direcionam ou criticam o comporta- } \\
\text { mento da criança. }\end{array}$ & $\begin{array}{l}\text { Acho que você vai gostar do mo- } \\
\text { rango, né?! }\end{array}$ \\
\hline Fantasiar & $\begin{array}{l}\text { Utilizar objetos mágicos ou de personagens do cotidiano } \\
\text { da criança no intuito de atribuir um caráter lúdico ao proce- } \\
\text { dimento }\end{array}$ & $\begin{array}{l}\text { Aperta o nariz para a cadeira mágica } \\
\text { subir. } \\
\text { Agora eu vou pegar o Bob Esponja! }\end{array}$ \\
\hline $\begin{array}{l}\text { Oferecer conforto emocional ou } \\
\text { contato físico }\end{array}$ & $\begin{array}{l}\text { Comportamentos verbais, ou não, nos quais se demonstra } \\
\text { que compreende os sentimentos da criança, e se utiliza de } \\
\text { afetividade com ela, tais como beijos, abraços e carinhos } \\
\text { (não incluindo contato físico no intuito de imobilização). }\end{array}$ & \\
\hline Elogiar & $\begin{array}{l}\text { Verbalizações dirigidas à criança que expressam apreciação } \\
\text { ou aprovação por seu comportamento ou característica } \\
\text { física. }\end{array}$ & Que dente mais lindo! \\
\hline $\begin{array}{l}\text { Distrair a criança com outro assunto/ } \\
\text { estímulo }\end{array}$ & $\begin{array}{l}\text { Fazer comentários não relativos os procedimentos clínicos } \\
\text { ou chamar atenção da criança para objetos/situações/ } \\
\text { pessoas não envolvidas no mesmo }\end{array}$ & $\begin{array}{l}\text { Vamos ficar bem bonito que aquela } \\
\text { tia vai filmar! } \\
\text { Olha só meu nariz de palhaço! }\end{array}$ \\
\hline \multicolumn{3}{|l|}{ Condutas Negativas } \\
\hline Crítica/restrição verbal & $\begin{array}{l}\text { Verbalização que salienta um aspecto negativo da criança } \\
\text { ou limita de alguma forma seu comportamento, apontando } \\
\text { algo que não deve ser feito. }\end{array}$ & $\begin{array}{l}\text { Tá doido! } \\
\text { Não morde o dedo da tia! }\end{array}$ \\
\hline Restrição/imobilização física & $\begin{array}{l}\text { Segurar alguma parte do corpo da criança durante a execu- } \\
\text { ção do procedimento utilizando, ou não, de materiais e } \\
\text { equipamentos apropriados para isto. }\end{array}$ & \\
\hline Ordens/direcionamentos & $\begin{array}{l}\text { Ordem, pedido ou sugestão, que indica qual comporta- } \\
\text { mento é esperado da criança direta ou indiretamente. }\end{array}$ & $\begin{array}{l}\text { Segura a girafa pra tia. } \\
\text { Deixa o bocão bem aberto, tá? }\end{array}$ \\
\hline Deixar a criança sozinha & $\begin{array}{l}\text { Solicitar que a criança permaneça sozinha na cadeira, e } \\
\text { deixar o lugar para buscar equipamentos ou conversar com } \\
\text { outras pessoas. }\end{array}$ & Fica quietinho que a tia já volta, tá? \\
\hline $\begin{array}{l}\text { Falar com outras pessoas sobre a criança } \\
\text { como se ela não estivesse presente }\end{array}$ & $\begin{array}{l}\text { Conversar com a mãe da criança ou com outros profissionais } \\
\text { durante a execução do procedimento clínico, sem explicar } \\
\text { a esta o conteúdo do diálogo. }\end{array}$ & $\begin{array}{l}\text { Olha, vocêtá vendo este dente aqui? } \\
\text { (dirigido para a mãe). }\end{array}$ \\
\hline
\end{tabular}

da pesquisa e requerendo-se a participação de seus filhos mediante a assinatura do Termo de Consentimento Livre e Esclarecido.

Cada uma das mães respondeu individualmente ao Walker Problem Behavior Identification Checklist (Walker, 1976). O instrumento foi aplicado mediante uma entrevista face a face com os responsáveis pela pesquisa. Pretendia-se, assim, identificar crianças que necessitassem de ajuda psicológica, descartando-as da pesquisa e encaminhando-as para atendimento psicotera- pêutico no Núcleo de Psicologia Clínica da Universidade Estadual de Londrina.

Posteriormente à seleção dos participantes, cada uma das díades foi submetida a uma sessão de filmagem de suas interações no decorrer da realização do procedimento odontológico. A fim de padronizar a coleta de dados observacionais, optou-se por restringir cada gravação aos dez minutos iniciais dos procedimentos, em função de ser essa a duração de alguns dos atendimentos. 
Tabela 2. Comportamentos das crianças categorizados quanto à cooperação/oposição diante do tratamento odontológico.

\begin{tabular}{|c|c|c|}
\hline \multicolumn{3}{|c|}{ Categorias infantis } \\
\hline Comportamento cooperativos & & Exemplos \\
\hline Falar & $\begin{array}{l}\text { Emissão de comportamento verbal espontâneo durante a } \\
\text { execução do procedimento (não incluindo temática de } \\
\text { protestos). }\end{array}$ & $\begin{array}{l}\text { Também tem uma escova lá na minha } \\
\text { casa!) }\end{array}$ \\
\hline Responder verbalmente & $\begin{array}{l}\text { Emissão de comportamento verbal em resposta a estímulo } \\
\text { verbal emitido pelo profissional. }\end{array}$ & $\begin{array}{l}\text { Você vai lembrar a tia de te dar um } \\
\text { desenho? (profissional) } \\
\text { Sim! (criança) }\end{array}$ \\
\hline Solicitar informação & $\begin{array}{l}\text { Questão verbal em que a criança pede informações acerca } \\
\text { do procedimento. }\end{array}$ & Para quê serve isso? \\
\hline Buscar suporte emocional & $\begin{array}{l}\text { Solicitação verbal ou não de abraço, beijo, colo ou outro } \\
\text { tipo de consolo do próprio profissional ou de outra pessoa. }\end{array}$ & Eu vou lá com a minha mãe! \\
\hline Olhar para a execução do procedimento & $\begin{array}{l}\text { Olhar dirigido para a execução do procedimento ou para os } \\
\text { equipamentos utilizados. }\end{array}$ & \\
\hline Auxiliar na execução do procedimento & $\begin{array}{l}\text { Comportamento verbal, ou não, da criança que indique sua } \\
\text { participação ativa na realização do procedimento. }\end{array}$ & Deixa que eu seguro a girafa! \\
\hline \multicolumn{3}{|l|}{ Comportamentos Opositores } \\
\hline Chorar/choramingar & Evocação de lágrimas e sons típicos não verbais. & Anh, anh, anh! \\
\hline Comportar-se de modo nervoso & $\begin{array}{l}\text { Manifestações físicas ou faciais de apreensão no que } \\
\text { concerne à realização do procedimento clínico. }\end{array}$ & \\
\hline Agredir fisicamente & $\begin{array}{l}\text { Ações que incluem emissão de comportamentos físicos } \\
\text { contra outras pessoas ou objetos, como morder, chutar, be- } \\
\text { liscar ou dar tapas. }\end{array}$ & \\
\hline Gritar & $\begin{array}{l}\text { Expressão vocal aguda de alta intensidade, sem emissão de } \\
\text { palavras. }\end{array}$ & \\
\hline $\begin{array}{l}\text { Fugir ou movimentar-se até a imobi- } \\
\text { lização }\end{array}$ & $\begin{array}{l}\text { Deixar a cadeira ou movimentar-se sobremaneira antes do } \\
\text { término do procedimento clínico. }\end{array}$ & \\
\hline Protestar & $\begin{array}{l}\text { Não seguimento das atividades propostas pelo profissional, } \\
\text { ou emissão de comportamento verbal em recusa ao mesmo. }\end{array}$ & $\begin{array}{l}\text { Pára! } \\
\text { Tá doendo! }\end{array}$ \\
\hline
\end{tabular}

Após a realização e filmagem de cada um dos procedimentos odontológicos, solicitou-se que o profissional preenchesse o Protocolo de Registro dos Comportamentos da Criança Durante a Realização do Procedimento Clínico (Jay et al., 1983).

Esse instrumento foi aplicado a fim de aferir a freqüência de comportamentos opositores ou cooperativos emitidos pelas crianças durante tal período de tempo, e verificar se realmente correspondiam às denominações cooperativa ou opositora que lhes foram inicialmente atribuídas. Ou seja, somou-se a pontuação obtida nas escalas likerts para cada um dos comportamentos infantis opositores, comparando-a com a pontuação total obtida nas escalas likerts para os comportamentos cooperativos. Nos casos em que a pon-

272 tuação foi maior para os comportamentos opositores, a criança era considerada opositora, e quando essa soma foi maior em relação aos comportamentos cooperativos, a criança foi considerada cooperativa. Caso o resultado do instrumento não corroborasse a denominação fornecida pelo odontopediatra, a criança era descartada da pesquisa, porém continuava a ser submetida a atendimento odontológico.

Duas observadoras previamente treinadas mediante a análise de trechos de interações de díades profissional-paciente não participantes da pesquisa procederam a categorização dos comportamentos dos profissionais e das crianças, registrando a freqüência de cada uma das respostas em questão, de acordo com a descrição e com os exemplos fornecidos nos quadros para Categorização das Condutas dos Profissionais e das Crianças (Ambrosano et al., 2004; Gongora \& Silvares, 1998; Jay et al., 1983). 
Após a categorização de todos os comportamentos profissionais e infantis, calculou-se o índice de fidedignidade para determinar a fidedignidade do material. Para tal fim, tomou-se o registro total de ambas as observadoras para cada uma das categorias especificadas, dividindo-se o valor de menor freqüência pelo de maior freqüência e multiplicando-se o resultado por cem. Nos casos em que o índice de fidedignidade foi inferior a 80\%, efetuou-se nova classificação, repetindo-se o cálculo para a nova categorização.

Conduziu-se uma análise funcional dos comportamentos das odontopediatras e seus pacientes.

\section{Resultados e Discussão}

Com relação à coleta de dados observacionais, uma informação de destaque refere-se à duração dos procedimentos odontológicos. Embora a categorização tenha se limitado aos dez minutos iniciais de cada procedimento odontológico, observou-se que para os sujeitos cooperativos tais procedimentos duraram aproximadamente dez minutos, enquanto para as crianças opositoras atendidas pela P1 e P2 os procedimentos atingiram respectivamente 18 e 14 minutos. Ou seja, observa-se um acréscimo de 40\% e 80\% no tempo de realização das intervenções clínicas para as crianças opositoras, representando intervalos duas e quatro vezes maiores do que os encontrados em pesquisas efetuadas por Ambrosano et al. (2004).

De acordo com esses mesmos autores, constata-se que acréscimos na duração dos procedimentos deixam o tratamento mais dificultoso e aumentam o estresse do paciente e do profissional. No presente estudo, por exemplo, observou-se uma freqüência mais elevada de comportamentos opositores por parte das crianças opositoras, acrescida a um menor número de interações positivas dirigidas a elas.

Um outro aspecto que merece ser destacado se refere ao Protocolo de Registro dos Comportamentos da Criança Durante a Realização do Procedimento Clínico, mediante o qual se observou que as crianças consideradas não cooperativas apresentaram uma média 100\% maior de comportamentos opositores do que as consideradas cooperativas. Entretanto, acerca das condutas de adesão, não houve diferença acentuada (apenas 30\%).

Em relação às categorizações dos comportamentos das crianças verificou-se uma discrepância de $163 \%$ entre os comportamentos cooperativos das crianças cooperativas e opositoras, com vantagens para as primeiras. Acerca das respostas de oposição, as observações não permitiram sequer o cálculo dessa estimativa, visto que seus índices correspondem a zero para as crianças cooperativas e 53 para as opositoras.

O emprego isolado do Protocolo de Registro dos Comportamentos da Criança Durante a Realização do Procedimento Clínico não permitiu identificar aspectos mais sutis da interação odontopediatra-paciente. Assim, considera-se que uma análise fundamentada na observação direta do comportamento da díade poderá indicar o modo como profissionais e pacientes influenciaram seus comportamentos reciprocamente (Meyer, 1997).

No que se refere à categorização da interação odontopediatra-paciente, por sua vez, observa-se que a freqüência de condutas positivas da P1 com a criança cooperativa (total de 27 respostas) é maior do que com a criança opositora (total de 12 respostas). Dessas, constata-se ainda que para a primeira criança são feitas sete descrições, 14 perguntas e seis utilizações de fantasia, enquanto para a segunda são efetuadas apenas seis descrições, três perguntas e três elogios (Figura 1).

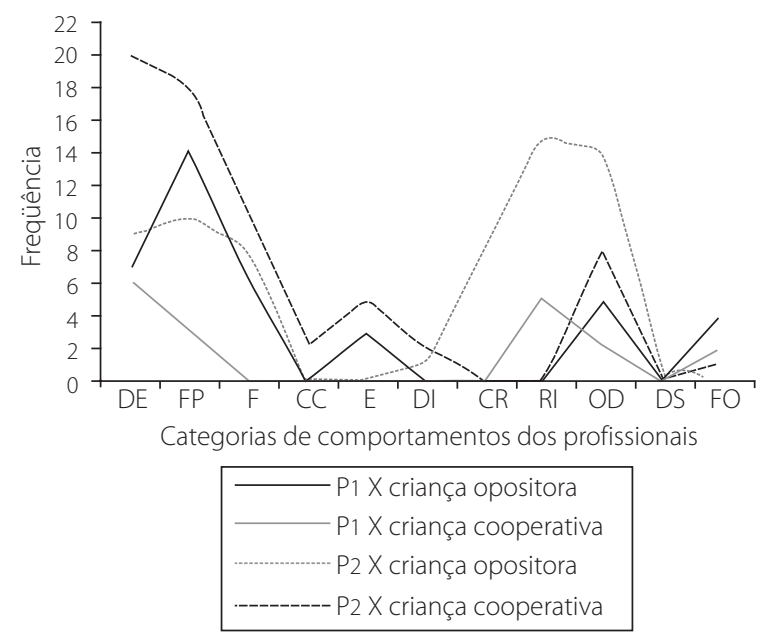

Figura 1. Freqüência das respostas de $\mathrm{P} 1$ e $\mathrm{P} 2$ com relação às crianças cooperativas e opositoras no decorrer de dez minutos de procedimento. 
Já as condutas negativas de P1 apresentam-se numericamente iguais tanto para o sujeito cooperativo quanto para o opositor (total de nove respostas). Todavia essas diferem em seu conteúdo, já que para o primeiro são realizadas cinco ordens ou direcionamentos e mais quatro respostas de interação com outras pessoas, e para o segundo são efetuadas cinco restrições físicas e imobilizações (uma a cada intervalo de dois minutos, e correspondendo à total duração deles), duas ordens ou direcionamentos, e duas condutas dirigidas às demais pessoas.

Para P2, por sua vez, verifica-se que o total de condutas positivas dessa profissional corresponde a 57 respostas dirigidas à criança cooperativa, e a apenas 28 direcionadas à criança opositora. Entretanto para a primeira são efetuadas 20 descrições, 18 perguntas, dez utilizações de fantasia, cinco elogios, duas distrações e duas respostas de conforto ou contato físico, ao passo que para o sujeito opositor são emitidas nove descrições, dez perguntas, oito utilizações de fantasia e uma distração.

Desse modo, constata-se que dentre as condutas positivas das profissionais mais freqüentemente empregadas estão o fazer perguntas, correspondendo a 45 respostas de um total de 124 e a descrição do procedimento e do funcionamento do equipamento, que representa outras 42 condutas desse mesmo total.

Observando-se ainda que muitas vezes essas perguntas visavam à confirmação de que a criança tinha conhecimento acerca das intervenções a serem efetuadas, considera-se que o presente artigo corrobora as observações de Weinstein et al. $(1982,1986)$ de que o fornecimento prévio de informação facilita a aquisição e a manutenção de comportamentos colaborativos com o tratamento.

Ao analisar as condutas negativas da P2, verificam-se apenas nove respostas no que concerne à criança cooperativa, e 38 no que se refere à opositora. Dessas, são observados oito direcionamentos ou ordens, e apenas uma interação dirigida a outra pessoa para o sujeito cooperativo; e oito críticas, 15 restrições ou imobilizações físicas, 14 direcionamentos ou ordens e uma resposta de deixar a criança opositora sozinha.

Conclui-se que os padrões negativos foram numericamente maiores para a criança opositora atendida pela P2, enquanto para P1 não houve diferença 274 no total de condutas negativas dirigidas à criança cooperativa ou opositora. Tal constatação poderia ser explicada, porém, pelo tipo de intervenção ao qual o sujeito opositor atendido por P1 foi submetido. Ele foi imobilizado durante todo o período de intervenção, não demandando que lhe fossem feitas ordens para que se comportasse de modo apropriado, ou mesmo críticas acerca de seus padrões não coniventes com o tratamento.

Sabe-se que muitas vezes a restrição física justifica-se quando a criança não adere a outra estratégia comportamental menos aversiva. Entretanto nenhuma tentativa diversa foi efetuada para o presente caso. Cabe destacar aqui, como o fazem Christiano e Russ (1998), que esse procedimento de imposição da restrição física expõe a criança à estimulação aversiva, o que, no entanto não garante a promoção de comportamentos de colaboração.

Isso pode ser exemplificado tanto pelo fato de o menino chorar durante todo o período de intervenção quanto por apresentar uma baixa taxa de comportamentos cooperativos. Suas respostas de cooperação consistiram em olhar a execução do procedimento, ou seja, possivelmente a única resposta de cooperação viável na situação de imobilização.

Importante ressaltar, porém, que a idade dessa criança (um ano e meio), mesmo sendo inferior à das outras, não justifica sua imobilização, uma vez que a prática clínica dentro desse mesmo contexto odontológico demonstra que pacientes de cerca de dez ou onze meses de idade já se submetem ao controle de conduta mediante a voz do profissional, quando submetidos a procedimentos indolores.

Verifica-se que das 80 respostas de cooperação apresentadas, predominam as categorias descritas como auxiliar na execução do procedimento (30 auxílios) e olhar para a execução do procedimento (21 olhares). Além disso, observa-se que desse total de respostas, 40 são emitidas pelo sujeito cooperativo (cinco falas, 11 respostas verbais, duas solicitações de informação, seis olhares e 16 auxílios) e 18 pelo opositor (três falas, uma resposta verbal, quatro solicitações de informação, três olhares e sete auxílios) atendido por P2, enquanto para P1 esses índices correspondem a um total de 18 (uma fala, duas respostas verbais, oito olhares e sete auxílios) e quatro condutas positivas (quatro olhares) respectivamente (Figura 2). 

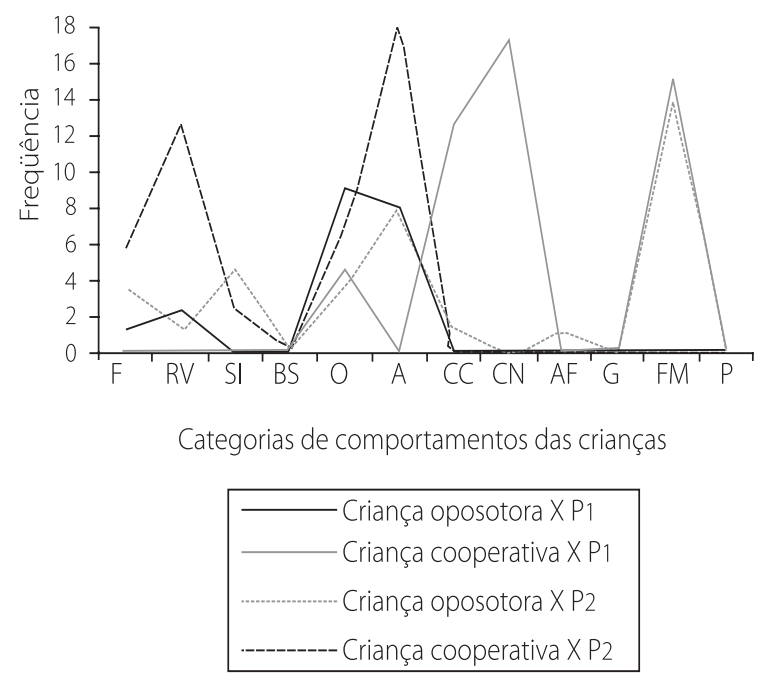

Figura 2. Freqüência das respostas das crianças cooperativas e opositoras com relação a P1 e P2 no decorrer de dez minutos de procedimento.

A Figura 2 evidencia ainda os comportamentos concorrentes das crianças atendidas. Não se verifica resposta de oposição emitida pela criança cooperativa, enquanto 39 são emitidas pelo sujeito opositor (11 choros/choramigos, 15 gritos e 13 fugas/movimentações) no que concerne a P1.

Com relação a P2, por sua vez, também não são constatadas condutas negativas provenientes da criança cooperativa, ao passo que se observam 14 comportamentos concorrentes advindos da criança opositora. Desses, um se remete ao choro/choramingo, um à agressão física e 12 à fuga/movimentação.

Assim, de um total de 53 respostas de oposição, observaram-se 25 tentativas de fuga ou movimentações até a imobilização e 15 gritos. Essas respostas são, talvez, as que mais dificultam a realização dos procedimentos, ampliando sua duração e expondo a criança por muito mais tempo à estimulação aversiva (Christiano \& Russ, 1998).

\section{Análise funcional das interações profissional-paciente}

Verificou-se que, de maneira geral, as crianças cooperativas, ao interagirem com os odontopediatras, receberam um maior número de condutas positivas por parte das profissionais quando comparadas às não cooperativas. Esse dado coaduna-se às afirmações de
Prins et al. 1987; Weinstein (1986) e Weinstein et al. (1982), segundo as quais as condutas positivas do profissional (fornecimento de informação, compreensão das reações emocionais, uso de fantasias, entre outros) facilitam a aquisição e a manutenção de comportamentos colaborativos com o tratamento, enquanto os padrões negativos (manejo inadequado, utilização de coerção e negação dos sentimentos da criança) potencializam as reações de medo, tais como gritos, choros e protestos.

Isso parece ocorrer devido ao fato de que os comportamentos positivos dos profissionais provavelmente contribuam para o estabelecimento de um ambiente agradável para as crianças, não sendo preciso se esquivar com choros, gritos ou outros comportamentos opositores. Ao contrário, elas parecem se sentir confortáveis e, desse modo, mais dispostas a falar, perguntar e colaborar, funcionando como conseqüência reforçadora positiva para aquelas respostas do profissional.

Uma vez que as crianças não se oponham à realização do procedimento odontológico, eliminam alguns dos fatores que poderiam funcionar como estímulos antecedentes para a emissão de comportamentos profissionais considerados negativos, e que englobariam a crítica ou a restrição física e/ou verbal, por exemplo. De maneira oposta, quando a criança coopera com o procedimento odontológico, seu padrão parece funcionar como ocasião que aumentaria a probabilidade de emissão de comportamentos positivos dos profissionais em relação a ela. Assim, sendo elogiada ou acariciada, a criança tem seu comportamento cooperativo reforçado positivamente, tendendo a desempenhá-lo de modo semelhante em situações análogas futuras.

Uma outra conseqüência benéfica dessa interação cooperativa dos profissionais e das crianças é tornar o contexto da clínica odontológica menos estressante para ambos (Christiano \& Russ, 1998). Considerando o efeito na criança, o contexto odontológico apresentaria, nesse caso, poucos eventos eliciadores de comportamentos respondentes de ansiedade e medo e poucos eventos sinalizadores para operantes de fuga ou esquiva.

Verificou-se que ambas as crianças atendidas pela P2 demonstram um índice mais elevado de comportamentos colaborativos do que as atendidas pela 
P1, visto que a primeira também emite um número maior de condutas positivas do que a segunda.

Do ponto de vista de uma análise funcional, seria possível levantar a hipótese de que os comportamentos opositores das crianças, dada uma possível não habituação ao contexto odontológico, funcionariam como eventos antecedentes a aumentar a probabilidade de emissão de condutas negativas de P1 e P2, tais como críticas e restrições físicas ou verbais, na tentativa de contê-las. Cessando momentaneamente a realização do procedimento odontológico, as respostas de choros ou gritos emitidas pelas crianças tendem a ser mantidas em função de suas conseqüências reforçadoras negativas.

Já as condutas negativas por parte dos profissionais, longe de levar à cooperação por parte das crianças, tendem a se constituírem eventos antecedentes à emissão de comportamentos opositores por parte dessas crianças, culminando no que Schrepferman e Snyder (2002) denominaram escalada de comportamentos coercitivos.

Por fim, como o profissional consegue executar todo o procedimento clínico - ainda que sob forte oposição das crianças -, seu comportamento, dadas tais conseqüências positivas, apresenta certa probabilidade de emissão em um contexto semelhante futuro. Além disso, o próprio comportamento opositor da criança poderia ser entendido como um estímulo aversivo do qual o odontopediatra acaba por se livrar ao fim da realização do procedimento clínico, tendo, assim, seu comportamento reforçado também negativamente.

\section{Considerações Finais}

Aparentemente, as variáveis dos profissionais não são as únicas responsáveis pelos comportamentos das crianças durante a intervenção, uma vez que eles também tiveram seu comportamento influenciado pelas condutas dessas crianças (Prins et al., 1987; Weinstein et al., 1982). As características do procedimento clínico adotado, a familiaridade com a clínica e com o odontopediatra são exemplos de outros possíveis fatores que influenciam a cooperação da criança.

Os dados aqui discutidos se focam em um desses

276 fatores - a interação entre o odontopediatra e seu paciente (Moraes, 1999). Do ponto de vista prático, os dados indicam que as condutas cooperativas ou positivas das crianças podem ser fomentadas seja por meio do comportamento do profissional seja pelo da criança. Aparentemente, cada situação de interação não cooperativa deve ser avaliada de modo singular. 0 presente estudo tratou da relação funcional entre os comportamentos de odontopediatras e seus pacientes, identificando-os em categorias. Estudos subseqüentes poderão isolar as categorias do comportamento do odontopediatra, tratando-as não como comportamentos, mas como eventos ambientais a serem manipulados experimentalmente.

Um planejamento da conduta do odontopediatra com a criança, com a finalidade de prevenir suas respostas opositoras, pode ser esboçado nesse momento. Sugere-se um uso mais intensivo de alguns dos procedimentos já adotados em odontopediatria, como: a) O emprego de estratégias lúdicas de distração da criança; b) O uso de estratégias lúdicas para familiarização da criança com o ambiente e com os procedimentos a serem adotados e c) A manipulação de variáveis, como a presença (ou ausência) da mãe na sala de atendimento odontológico.

Todavia são necessários estudos futuros que avaliem a efetividade dos procedimentos aqui sugeridos, uma vez que é possível que crianças excessivamente opositoras com relação ao tratamento odontológico estejam também sob controle de outras variáveis não diretamente relacionadas a esse contexto. Assim, talvez um trabalho psicológico prévio ou concomitante ao tratamento odontológico, e que atue na identificação e manipulação desses fatores, se mostre efetivo para esses casos extremos nos quais a adoção de estratégias por parte dos profissionais possa se mostrar insuficiente.

\section{Referências}

Academia Americana de Odontopediatria (1996). Guidelines for behavior management. Pediatric Dentistry (Specialissue), 18, 86-88.

Allen, K. D., Loiben, T., Allen S. J., \& Stanley, R. T. (1992). Dentist: implemented contingent escape for management of disruptive child behavior. Journal of Applied Behavior Analysis, 25 (3), 629-636.

Allen, K. D., Stanley, R., \& McPherson, K. (1990). Evaluation of behavior management technology dissemination in pediatric dentistry. Pediatric Dentistry, 12 (2), 79-82. 
Allen, K. D., Stark, L. J, Rigney, B. A., Nash, D. A., \& Stokes, T. F. (1988). Reinforced practice of children's cooperative behavior during restorative dental treatment. Journal of Dentistry for Children, 55 (4), 273-277.

Ambrosano, G. M. B., Costa Jr., A. L., Moraes, B. A., \& Possobon, R. F. (2004). O comportamento de crianças em tratamento odontológico: intervenção psicofarmacológica. Psicologia: Reflexão e Crítica 17, 75-82.

Berge, M. T., Veerkamp, J., \& Hoogstraten, J. (1999). Dentist's behavior in response to child dental fear. Journal of Dentistry for Children, 63, 36-40

Christiano, B., \& Russ, S. W. (1998). Matching preparatory intervention to coping style: the effects on children's distress in the dental setting. Journal of Pediatric Psychology, 23 (1), 17-27.

Costa, Jr. A. L. (2001). Análise de comportamentos de crianças expostas à punção venosa para quimioterapia. Tese de doutorado não-publicada, Universidade de Brasília.

Costa Jr., A. L., \& Coutinho, S. M. G. (2000). Você tem medo de dentista? A psicologia pode ajudar-Ihe. Leia: Informação e Crítica, 2 (9), 20-24.

Ferreira, Z. A., Carvalho, E. K., Mitsudo, R. S., \& Bergamo, P. M. S. (2006). Reforço de Ribbond: aplicação clínica. Acessado em Fevereiro 15, 2006, disponível em: http://www. oraltech.com.br/news/dica9/pag01.htm

Gongora, M. A. N., \& Silvares, E. F. M. (1998). Psicologia clínica comportamental: a inserção da entrevista com adultos e crianças. São Paulo: Edicon.

Ingersoll, B. D., Nash, D. A., \& Gramber, C. (1984). The use of contingent audiotaped material with pediatric dental patients. Journal American Dental Association, 109 (5), 717-720.

Jay, S. M., Ozolins, M., Elliot, C. H., \& Caldwell, S. (1983). Assessment of children's distress during painful medical procedures. Health Psychology, 2, 133-147.

Melamed, B. G., Hawes, R. R., Heiby, E., \& Glick, J. (1975). Use of filmed modeling to reduce uncooperative behavior of children during dental treatment. Journal of Dentistry Research, 54 (4), 797-801.

Meyer, S. B. (1997). O conceito de análise funcional. In M. Delitti (Org.), Sobre comportamento e cognição (pp.31-36). São Paulo: ARBYtes.
Moraes, A. B. A. (1999). Comportamento e saúde bucal: circunscrevendo o campo. In R. R. Kerbauy (Org.), Comportamento e saúde: explorando alternativas (pp.61-83). Santo André: Arbytes.

Moraes, A. B. A., \& Gil, I. (1991). Odontopediatria clínica. São Paulo: Santos.

Possobon, R. F., Moraes, A. B. A., Costa Jr., A. L., \& Ambrosano, G. M. B. (2003). O comportamento de crianças durante atendimento odontológico. Psicologia: Teoria e Pesquisa, 19, 59-64.

Prins, P., Veerkamp, J., Horst, G., Jong, A., \& Tan, L. (1987). Behavior of dentists and child patients during treatment. Community Dentistry of Oral Epidemiology, 15 (5), 253-257.

Schrepferman, L., \& Snyder, J. (2002). Coercion: the link between treatment mechanisms in behavioral parent training and risk reduction in child antisocial behavior. Behavior Therapy, 33, 339-359.

Stark, L. J., Allen, K. D., Hurst, M., Nash, D. A., Rigney, B., \& Stokes, T. F. (1989). Distraction: its utilization and efficacy with children undergoing dental treatment. Journal of Applied Behavior Analysis, 22 (3), 297-307.

Stokes, T. F., \& Kennedy, S. H. (1980). Reducing child uncooperative behavior during dental treatment through modeling and reinforcement. Journal of Applied Behavior Analysis, 13 (1), 41-49.

Thom, A., Sartory, G., \& Johren, P. (2000). Comparison between one-session psychological treatment and benzodiazepine in dental phobia. Journal of Consulting and Clinical Psychology, 68 (3), 378-387.

Walker, H. M. (1976). Walker problem behavior identification checklist (WPBIC): manual. Los Angeles: Western Psychological Service.

Weinstein, P. (1986). Integrating behavioral methodologies into dental pharmacological research. Anesthesia Progress, 33 (1), 55-59.

Weinstein, P., Getz, T., Ratener, P., \& Domoto, P. (1982). The effect of dentist's behaviors on fear-related behaviors in children. Journal of American Dentistry Association, 104 (1), 32-38.

Recebido em: 18/10/2005

Versão final reapresentada em: 25/7/2006

Aprovado em: 15/8/2006 
